thebmj

\title{
Editorials
}

\section{Health systems and increased longevity in people with HIV and AIDS}

BMJ 2009; 338 doi: http://dx.doi.org/10.1136/bmj.b2165 (Published 18 June 2009) Cite this as: BMJ 2009;338:b2165

\author{
R A Atun, professor of international health management 1 , I Gurol-Urganci, lecturer 2 , M McKee, \\ professor of European public health2 \\ ${ }^{1}$ Imperial College London, London SW7 2AZ \\ ${ }^{2}$ Department of Public Health and Policy, London School of Hygiene and Tropical Medicine, London WC1E 7HT
}

R A Atun rifat.atun@theglobalfund.org

Lessons can be learnt from the extensive experience in other chronic disorders

The introduction of antiretroviral therapy in the 1990s transformed the lives of people with HIV and AIDS.1 2 Whereas AIDS was once a rapidly progressive disease, with a life expectancy often measured in months, it has now become yet another chronic disease where effective, well tolerated, and widely available treatment allows those affected to lead relatively normal lives. Ninety years ago, a similar therapeutic breakthrough, the isolation of insulin, transformed the lives of those with type 1 diabetes. Now, models based on empirical data estimate that a 25 year old person with HIV, when appropriately treated with antiretroviral therapy, can expect to enjoy a median survival of 35 years, remarkably similar to that for someone of the same age with type 1 diabetes. 3

The benefits of antiretroviral therapy are not confined to the West. Although the mortality of patients starting therapy in sub-Saharan Africa is substantially higher than for those in industrialised countries, patients who start treatment when they have a high CD4 count and clinically early disease have an excess mortality in the second year of antiretroviral therapy that is similar to that of people without HIV.4 However, in sub-Saharan Africa, around $8 \%$ to $26 \%$ of patients die in the first year of therapy due to health systems delays in initiating antiretroviral treatment and because of the quality of the preceding and follow-up care. 5

The insulin analogy can be extended. Early enthusiasm about the obvious benefits of insulin eventually gave way to recognition that increased survival came at a cost. People with diabetes developed complications affecting many body systems and, as they aged, accumulated other chronic diseases that added to the complexity of their management.

History is repeating itself with HIV infection, with both HIV and antiretroviral therapy causing a range of short and long term adverse effects. 6 There is still much uncertainty about the optimal management of these problems, and their expected magnitude is considerable. In 2008, about 33 million people were living with HIVIAIDS, 7 with approximately 3.5 million in low or middle income countries on antiretroviral 
therapy supported by The Global Fund to Fight AIDS, Tuberculosis and Malaria and President Obama's PEPFAR project (President's Emergency Plan for AIDS Relief).8 As coverage of antiretroviral therapy and longevity increase, so will the number of older people with HIVIAIDS having this treatment. This number will include old people with AIDS who have coincident needs associated with old age, people who have had HIV for a long time and are developing problems related to long term therapy, and those who are old and exposed to treatment for a long time. This is uncharted territory for health systems in low, middle, and high income countries. Notwithstanding the ethical obligation and the predictable financing needed to keep all people with HIVIAIDS started on antiretroviral therapies, action is needed now systematically to address the growing needs of this group.

Unfortunately, the evidence base for policy is weak, as is guidance for managing ageing people with HIVIAIDS on antiretroviral therapy. A recent systematic review on the settings and organisation of care for people living with HIVIAIDS did not find any studies related to the ageing population with HIVIAIDS.9

This does not, however, mean that nothing can be done. An effective response by health systems to those growing older with AIDS can benefit from the much longer experience with other complex chronic diseases, such as diabetes-where the importance of integrated care approaches are well recognised. The best known example of this is perhaps the Chronic Care Model,10 in which four interacting system components-self-management support, delivery system design, decision support, and clinical information systems-are supported by adequate resources and effective policies. Yet this experience also supports caution. While many examples of success exist, health systems in some countries have struggled to put in place appropriate responses to the common, treatable chronic diseases, especially where funding mechanisms encourage competition rather than collaboration.

The availability of antiretroviral therapy, delivered by functioning healthcare systems, has transformed survival of people living with HIVIAIDS in low income and high income countries. Experience from Senegal, one of the first African countries to have antiretroviral treatment sponsored by government and later by international funding agencies, has shown the feasibility and effectiveness of long term treatment of individuals with HIVIAIDS, with clinical and biologic results in selected cohorts similar to those seen in Western countries.11 In Europe, countries such as Denmark,3 France, and the Netherlands have developed well functioning health systems that are able to initiate antiretroviral treatment of HIV affected individuals and successfully manage them in the long term, even though widespread inequalities of access still remain in Europe.12 In these examples, early initiation of treatment and close follow-up of those treated have been key to successful management of individuals treated with antiretroviral therapy.

The next challenge is to develop responses to the needs of this ageing population. From an organisational perspective, lessons can be learnt from dealing with other chronic disorders. However, this means that AIDS will need to be viewed as a new complex chronic disease, which may be the greatest challenge of all.

\section{Notes}

Cite this as: BMJ 2009;338:b2165

\section{Footnotes}

- Competing interests: None declared. 
- Provenance and peer review: Commissioned, not externally peer reviewed.

\section{References}

1. Sterne JA, Hernan MA, Ledergerber B, Tilling K, Weber R, Sendi $P$, et al. Long-term effectiveness of potent antiretroviral therapy in preventing AIDS and death: a prospective cohort study. Lancet2005;366:378-84.

2. Walensky RP, Paltiel AD, Losina E, Losina E, Mercincavage LM, Sax PE, et al. The survival benefits of AIDS treatment in the United States. J Infect Dis2006;194:11-9.

3. Lohse N, Hansen A-BE, Pedersen G, Kronborg G, Gerstoft J, Sorensen HT, et al. Survival of Persons with and without HIV Infection in Denmark, 1995-2005. Ann Intern Med2007;146:87-95.

4. Brinkhof MWG, Boulle A, Weigel R, Messou E, Mathers C, Orrell C, et al. Mortality of HIV-infected patients starting antiretroviral therapy in sub-Saharan Africa: comparison with HIV-unrelated mortality. PLoS Med2009;6:e1000066.

5. Lawn SD, Harries AD, Anglaret X, Myer L, Wood R. Early mortality among adults accessing antiretroviral treatment programmes in sub-Saharan Africa. AIDS2008;22:1897-908.

6. Effros RB, Fletcher CV, Gebo K, Halter JB, Hazzard WR, Horne FM, et al. Workshop on HIV infection and aging: what is known and future research directions. Clinical Infectious Diseases2008;47:542-53.

7. 2008 Report on the global AIDS epidemic. UNAIDS: Geneva; 2008. http://www.unaids.org/en/KnowledgeCentre/HIVData/GlobalReport/2008/2008 Global report.asp.

8. Low-Beer D, Atun R, Grubb I, Sempala MJ, Komatsu R, Banati P, et al. Scaling up for impact, The Global Fund results report 2009. The Global Fund to Fight AIDS, Tuberculosis and Malaria: Geneva; 2009.

9. Handford CD, Tynan AM, Rackal JM, Glazier RH. Setting and organization of care for persons living with HIVIAIDS. Cochrane Database Syst Rev2006;3:CD004348.

10. Bodenheimer T, Wagner EH, Grumbach K. Improving primary care for patients with chronic illness- the chronic care model, part 2. J Am Med Assoc2002;288:1909-14.

11. Laurent C, Ngom Gueye NF, Ndour CT, Gueye P, Diouf M, Diakhaté N, et al. Long-term benefits of highly active antiretroviral therapy in Senegalese HIV-1-infected adults. JAIDS2005;38:14-7.

12. Coker R, Atun R, McKee M. Health systems and the challenge of communicable diseases: experiences from Europe and Latin America. Maidenhead: Open University Press; 2008. 